\title{
Can virtual seminars be used cost-effectively to enhance student learning?
}

\author{
Peter Halfpenny and Sonja Wellings \\ University of Manchester \\ email:p.halfpenny@man.ac.uk
}

This paper describes a virtual seminar initiative designed to investigate the extent to which computer-mediated communication (CMC) can cost-effectively strengthen staffstudent interaction and enhance student group discussion, and thereby improve collaborative learning. After setting the scene by means of a brief review of the discursive potential of CMC, the establishment of an asynchronous bulletin board system on three modules in the Department of Sociology at the University of Manchester using industry standard software is described. Detailed time diaries kept by all staff involved revealed that organizing and running the virtual seminars were very much less time-consuming than running face-to-face seminars. However, analysis of the students' access to and usage of the virtual seminars indicates that some of them were disadvantaged by CMC and that they favoured face-to-face contact with lecturers over virtual seminars. The latter should therefore be part of a portfolio of teaching techniques rather than the sole form of collaborative learning. The conclusion is that a significant obstacle to benefiting from $C M C$ is the further demand on staff time that results from adding virtual seminars as a supplement to existing teaching practices. Even though these extra demands may be modest, effectively deploying the discursive potential of CMC to enhance student learning increases staff effort rather than reducing it, as many have hoped or promised it would.

\section{Introduction}

With the expansion of university student numbers over the past decade, deteriorating staff-student ratios have necessitated a re-evaluation of teaching and learning practices. In gencral, the amount of direct contact between staff and students has diminished. Lecture audiences have grown larger and there is less opportunity within or immediately after lectures for interaction between students and lecturers. Seminars, classes and tutorials have also grown and they often have fifteen or more students in them, allowing on average only four minutes or fewer of active participation by each member over the course of an hour's 
session. These sessions are also increasingly taught by postgraduate teaching assistants, rather than the lecturers responsible for the modules, and some have become fortnightly rather than weekly. Overall, the opportunities for students to engage actively in group discussions guided directly by academic staff have decreased substantially - even though this is widely recognized as one of the most effective learning experiences (Johnson and Johnson, 1990).

A potentially cost-effective way of reintroducing staff-guided student collaborative learning is through virtual seminars - discussions that take place electronically over the campus network. Virtual seminars have numerous virtues: they are independent of place and time in that students can contribute whenever they wish from wherever they can access a networked computer; they permit many-to-many communication and enable collaborative learning through text-based interactions; they promote thoughtful and reflective commentary and heighten critical awareness; they improve accessibility and learner control by making it difficult for one student to dominate the discussion and easier for shy students to contribute; and they encourage student-centred teaching (Davis, 1997; Duffy, Arnold and Henderson, 1995; Harasim, 1993; Pincas, 1997; Stainfield, 1997). These features can give computermediated communication (CMC) advantages over traditional face-to-face tutorials. As the Dearing Report noted, 'computer-based programmes, such as tutorials . . . can be highly interactive and provide activities that students need to develop their understanding of others' ideas and the articulation of their own' (Dearing, 1997, para 8.24).

\section{The coming revolution?}

Rapid advances in computing technology and the emergence of industry standard software over recent years has made educational applications of CMC more viable (Anderson and Jackson, 2000; Ehrmann, 1994). Students come to university ever more computer literate and with prior experience of the Web. Staff have increasing knowledge of information and communications technologies and universities have been putting the infrastructure and support in place.

Following these developments, there have been growing numbers of higher education courses that are computer-assisted. In some cases the technology is still being used as a repository, merely storing course materials, or an administrative tool for organizing teaching tasks. For example, Schneider (1998) describes how he set up a 'teaching home page' at the University of Texas Tech to provide course information which could be more easily accessed by students and readily updated to take account of current events and student feedback. Similarly, Browning and Williams (1995) suggest that CMC can be used to make lecture notes available to students for extra revision or to catch up if they have missed a lecture.

In other cases, the communicative potential of the technology is used to introduce an innovative learning environment centred on asynchronous collaborative activities. For example, Duffy et al. (1995) describe how on-line undergraduate seminars in music history at the University of Glasgow took place using NetSem, a widely available asynchronous conferencing system. The reasons for introducing the system were primarily pedagogical: the aim was to improve the quality of seminars by encouraging more active debate and developing critical thinking skills. Students particularly valued the flexibility and 
convenience that the system offered (many contributions being made late at night or over the weekend) and contributions were found to be relatively lengthy and well researched. The investigators reported that the seminars provided students with a 'dynamic' and 'enjoyable' experience and the staff involved concluded that seminar contributions produced interesting, informed and engaged argument.

It was the discursive potential of CMC allied with concerns about the economics of online education that prompted the initiative described below.

\section{The Manchester Sociology Department initiative}

In the 1998/9 academic year, the Department of Sociology at the University of Manchester was awarded funding by the University-based Enterprise Centre for Learning and Curriculum Innovation to introduce an asynchronous bulletin board system on selected modules. The aim was to investigate the extent to which $\mathrm{CMC}$ could cost-effectively strengthen staff-student interaction and enhance staff-guided student group discussion, on the assumption that this would improve learning.

After taking the advice of technical staff and reviewing what systems had been used previously in similar initiatives, three virtual seminars were set up on the faculty Web server by an information systems development officer using the Microsoft FrontPage bulletin board facility. The seminars could be accessed from any Internet-connected computer using standard Web browsers. Overall provision by the university at the time was approximately one networked computer per 12.5 students in the faculty.

\section{Participants and procedure}

One of the three selected modules was a final-year undergraduate course in Social Divisions (SD), taken by over fifty students. Teaching comprised a weekly one-hour lecture, following which the students were divided into four groups, each of which normally met for weekly one-hour face-to-face tutorials. After forming the tutorial groups, the members of one were told that the traditional face-to-face seminar was to be substituted in its entirety by a virtual seminar. The thirteen students in this group were given the option of switching to one of the remaining three face-to-face tutorial groups, but none did. To prevent the virtual seminar from being perceived by students as merely optional - something that could be ignored - they were instructed to take part in discussing each week's lecture topic online. However, participation was not mandatory and students were not individually chided if they did not join the discussion.

The second module was a postgraduate class of thirty-two students taking a course in Qualitative Research Methods (QRM). In this case, the virtual seminar acted as a supplement to the weekly two-hour teaching period in which there was a lecture followed by face-to-face discussion between students and the lecturer. The students were encouraged to use the virtual seminar to continue the discussion or raise further issues, after first introducing themselves and their research interests in the forum.

Finally, one virtual seminar was set up as an adjunct to a postgraduate course on Research Design (RD) taken by forty students. In this case, the students were informed that the seminar was available, but it was not incorporated into the teaching, which included lectures, demonstrations and class exercises in a weekly three-hour period. 
Two control groups were identified in order that a comparison could be made of the staff effort involved in running and maintaining virtual seminars with the effort involved in running face-to-face tutorials. In the case of SD, the control was one of the other three tutorial groups for that module, which met weekly for a one-hour face-to-face discussion between the students and a postgraduate tutor. In the case of QRM, the control was another postgraduate course with the same format of a weekly two-hour session that included both a lecture and a discussion period. For convenience this will be referred to as the QRM face-to-face seminar, though it was a module on Conversation Analysis. There was no control for the adjunct virtual seminar in RD.

All the virtual seminars took place in the second semester of the 1998/9 academic year for a period of ten teaching weeks. In each case the module lecturer acted as the moderator for the virtual seminar. At the beginning of the semester, all students attended a half-hour hands-on training session on how to access their virtual seminar, how to read contributions and make their own, and how to abide by the rules of 'netiquette'.

\section{Evaluation methods}

In order to monitor staff effort, all those involved in virtual seminar activity kept diaries in which they recorded the length of time taken on all virtual seminar-related activities. Staff responsible for the control groups also kept records of the time they spent preparing for and running their face-to-face seminars.

A short pre-seminar questionnaire was administered to students to assess their levels of computer literacy and to determine their access to networked computers. Students' use of seminars was monitored by a count of their contributions and simple content analysis of the discussion threads. Student evaluation of the virtual seminars was obtained by means of a self-completion questionnaire administered at the end of the semester. The outcome of the investigation into student evaluation of the virtual seminars is reported in more detail elsewhere (Halfpenny and Wellings, 2000). After briefly considering student usage, this paper focuses primarily on staff effort involved in setting up and running the virtual seminars and their cost-effectiveness in enhancing staff-student interaction.

\section{Access and usage}

Low levels of computer literacy, problems in accessing on-line learning facilities and technical difficulties experienced during use are commonly acknowledged limitations of many computer-based teaching initiatives. However, in this study, computer literacy was high: on the preliminary questionnaire, 97 per cent of the students involved reported that they used a computer for word-processing on a regular basis (that is, a few times a month or more), only 7 per cent said that they had never used the Web and 15 per cent that they had never used email. The technical support made available throughout the semester was called upon only once. Responses to the student evaluation questionnaire indicate that access was not a major difficulty for most participants in this study: 78 per cent of postgraduates and 80 per cent of undergraduates reported no problems, even though they relied on heavily used campus computer clusters, with only 8 per cent of undergraduates having a network connection off-campus, although this figure rose to 40 per cent for the postgraduates.

Usage of the virtual seminars varied, with the postgraduate QRM seminar attracting most contributions: overall, 91 per cent of the thirty-two students in the group contributed and 
between them they made seventy-four contributions. The SD virtual seminar attracted eighteen contributions from 54 per cent of the thirteen students in the group. The quality of usage mirrored the quantity: compared with the undergraduate SD virtual seminar, in the QRM postgraduate virtual seminar contributions were longer, discussion threads contained more contributions, and more topics were student-initiated rather than tutorinitiated. That the supplement QRM virtual seminar was both more used and more productively used than the substitute SD virtual seminar was unexpected, given that the latter group had no alternative means of accessing the module lecturer whereas the former group had a weekly face-to-face discussion period with their lecturer. This unanticipated finding confirms the result of previous studies which have shown that pedagogic conventions, including the prior learning experience and expectations of students, influences their engagement with on-line learning (Laurillard, 1993; Light, Colbourn and Light, 1997; McAteer, Tolmie, Duffy and Corbett, 1997). In this case, the postgraduates - who are more likely to take responsibility for their own learning than undergraduates - responded more fully to the opportunity to participate in the virtual seminar, even though they had more opportunities for face-to-face discussion than the undergraduates.

The RD adjunct virtual seminar, which unlike the other two virtual seminars was not promoted as an integral part of the teaching, was little used: only eleven contributions from 13 per cent of its forty student members. Because of the low usage, and the lack of a control group, the RD seminar is not discussed further.

There was a noticeable gender disparity among contributors to the $Q R M$ virtual seminar (although not in the SD and RD virtual seminars). The group as a whole comprised nincteen women ( 59 per cent) and thirteen men ( 41 per cent). Of the twenty-five known contributors (four others participated anonymously), ten were female ( 40 per cent) and fifteen were male ( 60 per cent). Males were also more likely to participate in the debates. Of the seventy-four contributions made, fifty-six came from male participants ( 76 per cent). Others have been alert to gender disparities in the use of CMC (for example, Light et al., 1997) and it might be that females perceive the technology as more suited to 'nerd' males.

The findings on access and usage reveal that some students were (at least initially) far less experienced computer users than others, a minority did report that access was a problem, nearly half the undergraduates did not actively participate in their virtual seminar, and women contributed to the postgraduate virtual discussions less than men. In other words, some students are disadvantaged by CMC and it is important to ensure that this is not to the detriment of their learning. Avoiding this entails integrating virtual seminars into a portfolio of tcaching techniques and not using CMC as the sole form of collaborative learning.

\section{Staff effort}

It required remarkably little staff time to set up the virtual seminars. Because lecturers had course material readily available on disk, it took the IS development officer (who had previous experience of FrontPage) no more than fifteen minutes per course to set up each virtual seminar and transfer course material to the site. No further maintenance of the sites was needed. The development officer also delivered the thirty-minute training sessions to each of the virtual seminar groups. Only one student asked for assistance subsequently, making an email enquiry concerning access. No other students or members of staff sought assistance of any kind. 


\begin{tabular}{|c|c|c|c|c|c|c|}
\hline \multirow[t]{2}{*}{ Seminar type } & \multicolumn{2}{|c|}{ The seminar } & \multicolumn{3}{|c|}{$\begin{array}{l}\text { Communicating with individual } \\
\text { students outside the seminar }\end{array}$} & \multirow[t]{2}{*}{$\begin{array}{l}\text { Total time } \\
\text { (minutes) }\end{array}$} \\
\hline & $\begin{array}{l}\text { Seminar } \\
\text { preparation and } \\
\text { administration }\end{array}$ & $\begin{array}{l}\text { Running } \\
\text { the } \\
\text { seminar }\end{array}$ & $\begin{array}{l}\text { Academic } \\
\text { matters }\end{array}$ & $\begin{array}{l}\text { Non- } \\
\text { academic } \\
\text { matters }\end{array}$ & Other* & \\
\hline SD virtual & 5 & 150 & 5 & - & 10 & 170 \\
\hline SD face-to-face & 657 & 565 & 110 & 65 & 200 & 1597 \\
\hline QRM virtual & 30 & 76 & 172 & 41 & 10 & 329 \\
\hline QRM face-to-face & 410 & 1200 & $205 * *$ & & 0 & 1815 \\
\hline
\end{tabular}

*For virtual seminars 'other' was replying to emails; for face-to-face seminars 'other' was mainly photocopying. **For the QMR face-to-face control group, the lecturer did not distinguish between the time spent on academic and non-academic matters.

Table 1: Time (in minutes) spent on seminar activities.

Staff diary records reveal that the time they spent organizing and running seminars, and communicating with seminar students, was considerably less for the virtual seminars than for the control face-to-face seminars (see Table 1). This is clearest in the case of SD, where the virtual seminar was a substitute for a face-to-face one. The total time spent by the virtual seminar tutor on all seminar-related activities (170 minutes) was around a tenth of the time spent by the face-to-face tutor (1,597 minutes). Substituting a face-to-face seminar by a virtual one resulted in a major saving of staff time.

Face-to-face SD seminar preparation involved spending time planning how to use the weekly discussion periods, which was not necessary for virtual seminars. Face-to-face seminar administration involved keeping a register of attendance and writing to absentees, whereas there was less check on virtual seminar 'attendance' and messages were quickly transmitted to students via the bulletin board or by email. Even if the time taken to set up the SD virtual seminar (less than fifteèn minutes) and the student training (thirty minutes) is included, the total time devoted to the preparation for and administration of the substitute virtual seminar (fifty minutes) was substantially less than for the control face-toface seminar (657 minutes).

Running the substitute SD virtual seminar took much less time (150 minutes) than being present throughout the weekly face-to-face tutorials (565 minutes), although it should be noted that the time spent running the virtual seminar might have increased had students made more use of it.

Time spent talking with individual students outside the SD seminar about academic and non-academic matters was much greater for the face-to-face seminar (175 minutes) than the virtual seminar (five minutes), probably because the face-to-face tutor was on hand to be approached. To a modest extent face-to-face talk was replaced by email communication between individual students and the virtual seminar tutor (ten minutes).

The face-to-face SD tutor spent over three hours (200 minutes) photocopying material for the seminar, a task which the virtual seminar tutor was spared because material on disk could be posted on the bulletin board in seconds. Even had the virtual seminar tutor chosen to distribute material that was initially in print form, scanning and posting it on the 
bulletin board would have taken much less time than making multiple photocopies of it. Conversely, if the photocopying had been done by central support services and therefore removed from the time cost of the face-to-face seminar, the total time of running the substitute SD virtual seminar (170 minutes) would still have been only about an eighth of the total time taken for the face-to-face seminar (1,397 minutes). Moreover, arranging for the photocopying to be done centrally would have cost the face-to-face seminar tutor at least a little time.

These findings contradict the common claim (for example, by Timms, 1997) that computer-based teaching and learning is more costly in time than traditional methods. One reason is probably that often in the past custom software has been developed - a timeconsuming approach - whereas in this study a simple proprietary package was used. Also, it is important to compare like with like. In this study, the time taken to prepare module outlines and lectures, and to set and mark essays and examinations, has been omitted because these activities are common to the course regardless of the form of the seminar. However, all seminar-related activities have been included in the comparison, not just the discussion face-to-face and on-line. Nevertheless, a more thorough-going costing would be possible, that included the time needed to support and maintain the university computer clusters and the campus network (as opposed, perhaps, to supporting and maintaining the tutorial rooms). Similarly, money costs have not been included.

In the case of QRM, the figures in Table 1 need to be interpreted carefully. The time spent preparing for, administering and running the supplement virtual seminar (106 minutes) was in addition to the time spent on preparing for, administering and running the weekly two-hour teaching session that included both a lecture and a face-to-face discussion period. The latter took 1,610 minutes in the control group. This indicates that a supplement virtual seminar adds only modestly to the time involved in running a postgraduate course - only an additional 7 per cent. However, again it should be noted that the time spent running the virtual seminar might have increased had students made more use of it.

Time spent talking with individual students outside the QMR seminar about academic and non-academic matters was approximately the same for the virtual seminar (213 minutes) as for the face-to-face seminar ( 205 minutes). This indicates that if the lecturers are physically present, as both were in the weekly two-hour teaching periods, then students take the opportunity to talk to them. In the case of the QMR virtual seminar, face-to-face talk was supplemented by only a modest amount of email communication between individual students and the virtual seminar tutor (ten minutes). This suggests that, as seen earlier with SD, face-to-face communication with tutors is preferred by students over email.

\section{Cost}

The study demonstrates that, as a substitute for face-to-face seminars, virtual seminars are much less costly in academic staff time: less than three hours for a virtual seminar compared with nearly twenty-seven hours for a weekly one-hour face-to-face seminar over a ten-week period. The time savings are realized in all activities related to the seminar: preparation, administration, running the seminar and communicating with individual students outside the seminar about academic and non-academic matters. The extra cost in support staff time in setting up the virtual seminar, posting teaching materials and training students in how to use the seminar is negligible, at less than one hour. 
However, there are two caveats. First, the virtual seminars in this study were relatively little used. Had the discussion threads been more numerous or more extended, then the staff time in contributing to and guiding them would have increased. Nevertheless, it is unlikely that running even a very active virtual seminar would absorb anything close to the time taken to run a face-to-face seminar. The highest use of a virtual seminar, in the QRM module, amounted to 74 contributions over a ten-week period, at a cost in staff time of 4.4 minutes per student contribution on average. Assuming that the time per contribution remained equal to this, there would need to be 408 contributions over the semester (equivalent to 12.8 contributions per student) before the total staff time running the virtual seminar surpassed that running the face-to-face seminar.

Second, for a combination of technical, pedagogic and equal opportunity reasons, virtual seminars are better integrated into teaching when used as a supplement to, rather than a substitute for, face-to-face seminars. Given this, the time taken in running a virtual seminar would be additional to the time given to other means of teaching - they represent a further demand on academic staff. Suggestions that $\mathrm{CMC}$ could ease the burden on staff caused by falling staff/student ratios while maintaining the quality of teaching raise false hopes.

\section{Effectiveness}

It was not an objective of the study to test the effectiveness of virtual seminars in terms of learning outcomes. Instead, the principal aim was more narrowly focused: to assess their effectiveness in giving students greater access to lecturer-guided discussion, on the assumption that this enhances collaborative learning. Some of the findings are positive: over all three virtual seminars, 44 per cent of the students who responded to the evaluation questionnaires said that they enjoyed being able to make contributions in their own time, 40 per cent reported that they found the quality of contributions from others to be of a high standard, and 30 per cent said that the contributions increased their understanding of the subject. All these percentages were higher for the more actively used virtual seminars. However, only 17 per cent overall thought that the virtual seminar gave them better access to the lecturer, the majority of this small percentage being students in the SD substitute virtual seminar who had no other means of direct access to their lecturer. Moreover, 83 per cent of the members of the two actively used virtual seminars. (QRM and SD) said that they would have preferred to attend a face-to-face seminar. Meeting a tutor in a face-toface seminar generates additional contact too: in the case of the undergraduate SD module, over the course of the semester the face-to-face seminar tutor spent 110 minutes communicating with individual students about academic matters and sixty-five minutes about non-academic matters, whereas the virtual seminar tutor spent just five minutes on the first of these and no time on the second, and only ten minutes on email communication with individual students by way of compensation for the lack of face-to-face contact.

The findings demonstrate that whatever the benefits of incorporating virtual seminars into the range of teaching methods employed on a module, students still value face-to-face discussion with their lecturers and tutors, in class and individually. However, a caveat is appropriate here too. If virtual seminars become more prevalent, students might become more favourable towards them than indicated by the results above, which are based on relatively little used virtual seminars in an environment where the students had not experienced them before. Although the present evidence suggests that face-to-face contact 
with lecturers is still greatly favoured by students over CMC, further study will be needed as virtual seminars become more prevalent.

\section{Conclusion}

The ease with which virtual seminars can be set up and the growing use of the Internet make it likely that more and more lecturers will use CMC over the coming years. This was encouraged by the Dearing Report, which called for higher education institutions to develop suitable C\&IT strategies at national and local level, and to adopt these technologies as teaching and learning resources. However, the findings from this study, together with the results of past evaluations, suggest that $\mathrm{CMC}$ is not a cost-effective remedy to the crosion of staff-student ratios.

Many commentators see the obstacles to the effective integration of CMC purely in terms of the lack of resources to provide better technological infrastructure and access, and appropriate training and support for both staff and students. Others take a broader view, raising concerns that the current culture of teaching and learning within universities is a more substantial barrier to the full potential of CMC being realized than lack of resources (Crook, 1997; Laurillard, 1993; Light et al., 1997; Timms, 1997; Weller, 2000).

This study suggests that there is a third problem, beyond the resources for C\&IT and the culture of teaching and learning. The constant search for cheaper ways of delivering higher education has generated widespread enthusiasm for computer assistance for several decades. Yet this study, like others before it, reveals that even a shift from using computers to store information to employing them as aids to discussion misses a key component of quality education - face-to-face interaction between teachers and learners. The collaborative learning opportunities provided by classroom-based tutorials can be usefully supplemented but not adequately substituted by CMC. Supplementary virtual seminars require an extra input by academic staff which, though modest, is still an increase in the demands upon their time. The third problem is, then, that computers cannot replace academic staff, and that the effective integration of $\mathrm{CMC}$ into teaching and learning increases staff effort rather than reduces it.

\section{Acknowledgements}

The authors wish to thank the Enterprise Centre for funding; Shoba Arun, Nick Crossley, Fiona Devine and Rod Watson for participating as seminar tutors; Nick Gould, the Faculty Information Systems Development Officer, for support; and all the students involved for their participation.

\section{References}

Anderson, M. and Jackson, D. (2000), 'Computer systems for distributed and distance learning', Journal of Computer Assisted Learning, 16, 213-28.

Browning, P. and Williams, J. (1995), 'The geology@bristol experience', Active Learning, 2 (July), 34-8.

Crook, C. (1997), 'Making hypertext lecture notes more interactive: undergraduate reactions', Journal of Computer Assisted Learning, 13, 236-44. 
Davis, N. (1997), 'Do electronic communications offer a new learning opportunity in education?', in B. Somekh and N. Davis (eds), Using Information Effectively in Teaching and Learning, London: Routledge.

Dearing, R. (1997), The Report of the National Committee of Inquiry into Higher Education, London: HMSO.

Duffy, C., Arnold, S. and Henderson, F. (1995), 'NetSem: electrifying undergraduate seminars', Active Learning, 2, 52-48.

Ehrmann, S. (1994), 'Looking backwards: US efforts to use technology to transform undergraduate education', in J. Martin, J. Darby and B. Kjollerstrom (eds), Higher Education 1998 Transformed by Learning Technology, Oxford: CTISS Publications.

Halfpenny, P. and Wellings, S. (2000), Using Virtual Seminars to Enhance Student Learning, Manchester: Centre for Applied Social Research, University of Manchester.

Harasim, L. (1993), Global Networks: Computers and International Communication, Cambridge, Mass.: MIT Press.

Johnson, D. W. and Johnson, R. T. (1990), 'Co-operative learning and achievement', in S. Sharan (ed.), Cooperative Learning: Theory and Research, New York: Praeger.

Laurillard, D. (1993), Rethinking University Teaching: A Framework for the Effective Use of Educational Technology, London: Routledge.

Light, P., Colbourn, C. and Light, V. (1997), 'Computer mediated tutorial support for conventional university courses', Journal of Computer Assisted Learning, 13, 228-35.

McAteer, E., Tolmie, A., Duffy, C. and Corbett, J. (1997), 'Computer-mediated communication as a learning resource', Journal of Computer Assisted Learning, 13, 219-27.

Pincas, A. (1997), 'Institutional design for group-based learning by computerconferencing', in C. Bell, M. Boroden and A. Trott (eds), Independent Flexible Learning, London: Kogan Page.

Schneider, A. (1998), 'Sociology: the internet as an extended classroom', Social Science Computer Review, 16, 40-52.

Stainfield, J. (1997), 'Using IT to manage a third year module', Active Learning, 6, 30-4.

Timms, D. (1997), 'C\&IT and the learning society - some post-Dearing thoughts', SocInfo Journal, 3 (December), 2-11.

Weller, M. (2000), 'Implementing a CMC tutor group for an existing distance education course', Journal of Computer Assisted Learning, 16, 178-83. 